\title{
DOS VISIONES DE LOPE DE AGUIRRE A TRAVÉS DEL CINE EUROPEO: WERNER HERZOG Y CARLOS SAURA
}

\author{
María Dolores Pérez Murillo ${ }^{1}$ \\ Universidad de CÁdIZ
}

\section{RESUMEN}

El presente artículo nos muestra la importancia del cine como fuente histórica y como recurso pedagógico. Un mismo personaje y acontecimiento histórico como es la figura de Lope de Aguirre y la expedición en busca de El Dorado tienen dos lecturas distintas desde el Cine: por un lado está la versión del cineasta alemán, Werner Herzog que en 1972 con Aguirre, la cólera de Dios, se centra en el contexto paisajístico y, sobre todo, en el estudio de la locura del poder. Por otro lado el cineasta español, Carlos Saura, en 1988 con su película El Dorado pretende ser más fiel a la crónica histórica con una espectacular puesta en escena.

\footnotetext{
1 María Dolores Pérez Murillo es Profesora Titular de Historia de América de la Universidad de Cádiz, Directora del Grupo de Investigación "Intrahistoria, Oralidad y Cultura en América Latina y Andalucía" (P.A.I/HUM 313); miembro del proyecto de Excelencia de la Junta de Andalucía: "Andalucía y América Latina, Intercambios y Transferencias Culturales" (HUM-03215), vinculado al CSIC (Escuela de Estudios Hispano-Americanos de Sevilla). Miembro del I+D+I de la Universidad de León: "La Tradición Clásica y Humanística en España e Hispanoamérica". Igualmente ha dirigido más de 10 Tesis de Máster y 7 Tesis Doctorales. Ha escrito 7 libros (4 como única autora y otros tres como coordinadora además de coautora); igualmente tiene más de 70 publicaciones entre artículos en revistas especializadas, actas de Congresos, colaboraciones en obras colectivas, reseñas y prólogos de libros. Ha impartido docencia en postgrados de Universidades españolas además de Cádiz, en la Hispalense, y en la Universidad Pablo de Olavide. Y en Universidades Latinoamericanas como : Universidad Estatal de Cuenca (Ecuador), Comunidad Indígena de Saraguro de la provincia de Loja, Zamora, Chimchipe (Ecuador); Universidad Nacional de San Juan, Universidad Nacional de Río Cuarto (Argentina); Universidade do Vale do Sinos -UNISINOS- (SaoLeopoldo-Rio Grande do Sul - Brasil), Universidade Federal de Santa Catarina (Florianópolis-Brasil); Universidad Nacional del Zulia (Maracaibo-Venezuela). Participación como ponente en más de 50 Congresos Internacionales celebrados en España, Europa y América Latina.
} 
PALABRAS CLAVES: Cine europeo como fuente y recurso didáctico para la historia colonial de América.

\section{ABSTRACT}

The present article shows us the importance of the movies as historic source and like pedagogical resource. A same personage and historic event as is the figure of Lope of Aguirre and the expedition in search of The Golden one they have two different readings since the Movies: on the one hand is the version of the German filmmaker, Werner Herzog that in 1972 with Aguirre, the rage of God, itself center in the landscape context and, above all, in the study of the insanity of the power. On the other hand the Spanish filmmaker, Carlos Saura, in 1988 with its movie The Golden one intends to be more faithful to the historic chronicle with a spectacular one put in scene.

KEY WORDS: European movies as source and didactic resource for the colonial history of America.

\section{INTRODUCCIÓN}

La siguiente investigación se enmarca en un amplio proyecto que, desde 1998, venimos realizando y coordinando en la Universidad de Cádiz, concretamente dentro del Grupo de Investigación Intrahistoria, Oralidad y Cultura en América latina y Andalucía. La apuesta por el cine como apoyo pedagógico y fuente auxiliar de la investigación histórica ha sido un gran acierto, no sólo por la frescura que posee esta innovadora forma de acercarse a la Historia, sino también por la rigurosidad de su análisis más allá del hecho histórico narrado.

La metodología empleada ha consistido en conocer a fondo primero al personaje y a los hechos históricos que se muestran en sendos films, con el objetivo de analizar a la luz de la documentación histórica las elipsis, tan propias del séptimo arte. En segundo lugar hemos profundizado en conceptos básicos del lenguaje cinematográfico, además del conocimiento de la obra y trayectoria de los dos directores, Werner Herzog y Carlos Saura. Tras visionar ambas películas, y estando bien documentada sobre la Historia que se cuenta y la forma de narrar del arte cinematográfico, hemos podido transcender la visión superficial, para detenernos en el paisaje, la ambientación, banda sonora, la intención y simbología de los planos y secuencias, al igual que los movimientos de cámara, y, sobre todo, hemos pretendido en todo momento centrarnos en los diálogos y en la interpretación que de Lope de Aguirre hacen el Klaus Kinski de Herzog y el Omero Antonutti de Carlos Saura.

La obra de Werner Herzog responde a las características del denominado cine de autor; y a pesar de ser un film para cinéfilos, sin embargo le dio fama internacional a su autor.

La obra de Saura tiene una espectacular puesta en escena, fue la más costosa del cine español hasta el momento, y su objetivo tenía unos claros fines de comerciales, sin que ello merme el rigor histórico de la narrativa. 
El Aguirre del teutón tuvo un doble escenario de rodaje. Así pues, las primeras escenas se filmaron en la vertiente oriental de los Andes peruanos, la denominada ceja de selva, que se inicia en Machu-Picchu y desciende por escarpadas laderas hacia la selva; las restantes escenas del film están rodadas en la propia selva amazónica: Andes y Amazonía adquieren el valor de verdaderos protagonistas. Desde el punto de vista del paisaje en fue rodada tiene más verosimilitud con la historia real que El Dorado de Carlos Saura que eligió como escenario de rodaje las selvas de Costa Rica.

\section{1.- CONTEXTOS HISTÓRICO Y GEOGRÁFICO PARA COMPRENDER LAS ELIPSIS DE LAS PELÍCULAS DE WERNER HERZOG Y CARLOS SAURA SOBRE “AGUIRRE” Y "EL DORADO”}

Ambas películas ${ }^{2}$ nos cuentan los hechos acaecidos durante la expedición en busca del mítico El Dorado realizada entre 1560-1561. La referida expedición estuvo dirigida en un principio por el navarro Pedro de Ursúa (Orsúa), siendo éste el principal financiador de la misma. En los films de Herzog y de Saura poco o nada se nos habla del pasado de los personajes; pero gracias a las crónicas hoy sabemos que Pedro de Ursúa fue un joven capitán navarro, con grandes éxitos militares en su haber, pues había luchado contra los indios de la Nueva Granada y había vencido a los negros cimarrones de Panamá. Llegó a ser gobernador de Santa Fe (actual Bogotá), fundó la ciudad de Pamplona en 1549. Tras ostentar el cargo de justicia mayor de Santa Marta, decidió pasar del marco geográfico neogranadino al peruano en 1558.

Por el contrario, Lope de Aguirre no tenía pasado "glorioso". Nacido en Oñate, este vasco de familia hidalga, venida a menos, o sea hidalgo de capa raída, representa más al grupo mayoritario que compuso la hueste española en las Indias. Llegado al Perú en 1537, se vio envuelto en las guerras de banderías entre pizarristas y almagristas. Guerras entre caudillos locales que en nada favorecieron a la gran mayoría de militares enrolados en las mismas, y, sobre todo, a aquellos que defendían el "pendón real". Pronto Lope de Aguirre comprobó las nulas recompensas que recibían militares como él; mientras que los tibios eran los que triunfaban en el nuevo orden colonial. Aguirre desempeñó también el oficio de domador de potros, acabó teniendo problemas con la legalidad, por lo que huyó de Cuzco y, para formalizar su situación, se alistó en las tropas de la expedición de Pedro de Ursúa, a pesar de su mala fama. En este viaje hacia El Dorado le acompañaba su única hija, Elvira, de 15 años, nacida en Cuzco y de raza mestiza y no aria como la muestra la película de Werner Herzog.

Las obras de Carlos Saura y de Werner Herzog nada nos cuentan acerca de cómo se financió la expedición y las razones de la misma, una expedición rezagada en el tiempo, pues en la década de los sesenta del siglo XVI ya hacía años que se habían acabado las grandes epopeyas conquistadoras. Sobre lo primero, decir que fue el propio Pedro de Ursúa quien se encargó de financiar tal empresa con dinero de algunos eclesiásticos y

2 Hay referencias a la película El Dorado de Carlos Saura en: PÉREZ MURILLO, María Dolores y FERNÁNDEZ FERNÁNDEZ, David (coordinadores): La Memoria Filmada: América latina a través de su cine. Madrid, Editorial IEPALA, 2002. 379 págs. Sobre la película Aguirre, la cólera de Dios hay referencias en: PÉREZ MURILLO, María Dolores (coordinadora y coautora): La Memoria Filmada II: Historia SocioPolítica de América Latina a través de su cine. La visión desde el Norte. Madrid. Editorial IEPALA, 2009. 459 págs. 
de un alcalde de Perú, Alonso de Montoya (el personaje que, castigado por Lope de Aguirre, acabará, según la ficción cinematográfica, remando con los negros esclavos en ese viaje a la deriva en busca de El Dorado). La idea de la expedición estaba en la mente de las más altas autoridades del Perú, entre ellas el mismo virrey Hurtado de Mendoza II Marqués de Cañete, el gran pacificador del Perú, que durante su mandato (1555-1561) tuvo como principal objetivo alejar a los soldados que "habían sobrado" de las guerras entre pizarristas y almagristas; soldados desocupados y que suponían un germen de revueltas y de bandolerismo, lo que en esa época se denominó limpiar la tierra de personas conflictivas. Así pues, aprovechando las noticias que se contaban de los indios brasiles y de El Dorado, a todos estos militares ociosos y pendencieros, unos 400 aproximadamente, se les agrupó y se les envió tras el mítico lugar. Los “marañones” de Lope de Aguirre son un claro ejemplo de estos hombres que se hallaron sin lugar en la nueva sociedad colonial en la que el conquistador comenzaba a ser reemplazado por el burócrata que garantizaba la unidad y el nuevo orden colonial bajo la monarquía hispánica.

Tampoco observamos en sendas películas el final de la expedición. En la obra de Carlos Saura una voz en off nos cuenta que Aguirre acabó muerto por las tropas del rey. En realidad, no fue así. Tras salir al mar, los marañones se dirigieron a través de El Caribe hacia Isla Margarita y Nueva Valencia (en la actual Venezuela). Nuevas muertes acontecieron en ese círculo de violencia desatado por Lope de Aguirre, y, ante la imposibilidad de llegar a Panamá por estar alertadas las autoridades coloniales, Aguirre decidió llegar al Perú atravesando Nueva Granada, una auténtica locura. Cercada su mermada hueste, serán los propios marañones, sus propios soldados, quienes le den muerte, después de haber matado el mismo Aguirre a su hija, Elvira, en Barquisimeto (actual Venezuela).



Mapa de la Expedición real de Lope de Aguirre: Partiendo de los Andes llegó a la selva amazónica surcando todo el Amazonas hasta su desembocadura en el Mar Caribe para después costear hasta Nueva Valencia (Venezuela). 
Respecto a las fuentes o crónicas de la expedición, la obra de Saura es más fidedigna que la de Werner Herzog, pues el primero tiene en cuenta a uno de los cronistas de la misma, como fue Pedrarias de Almesto (Pedro Arias de Almesto), nacido en Zafra (Badajoz) en 1540, que cuando contaba 20 años se enroló en la expedición como escribano de la misma primero al servicio de Pedro de Ursúa y después de Lope de Aguirre, como testigo presencial de todo lo ocurrido escribió su crónica: Relación verdadera de todo lo que sucedió en la jornada de Omagua y Dorado que el gobernador Pedro de Orsúa fue a descubrir... Tratase asimismo del alzamiento de don Fernando de Guzmán y Lope de Aguirre, y de las crueldades de estos perversos tiranos. También Francisco Vázquez, es el otro cronista de esta expedición. Hay que señalar que en la película de Werner Herzog existe un desconocimiento de las fuentes y profundo anacronismo, pues al intentar dar veracidad a lo que cuenta se basa en la expedición de Gonzalo de Pizarro y de Francisco de Orellana, "descubridor" este último del Amazonas, expedición que tuvo lugar 18 años antes que la de Pedro de Ursúa y Lope de Aguirre. Siguiendo con el error histórico la película de Herzog considera al dominico Gaspar de Carvajal cronista oficial de la expedición de Lope de Aguirre. La figura del vasco Aguirre y su búsqueda de El Dorado han generado obras literarias como las de Ramón J. Sender, Abel Posse, Uslar Pietri, y Otero Silva.

\section{2.- AGUIRRE, LA CÓLERA DE DIOS SEGÚN WERNER HERZOG}

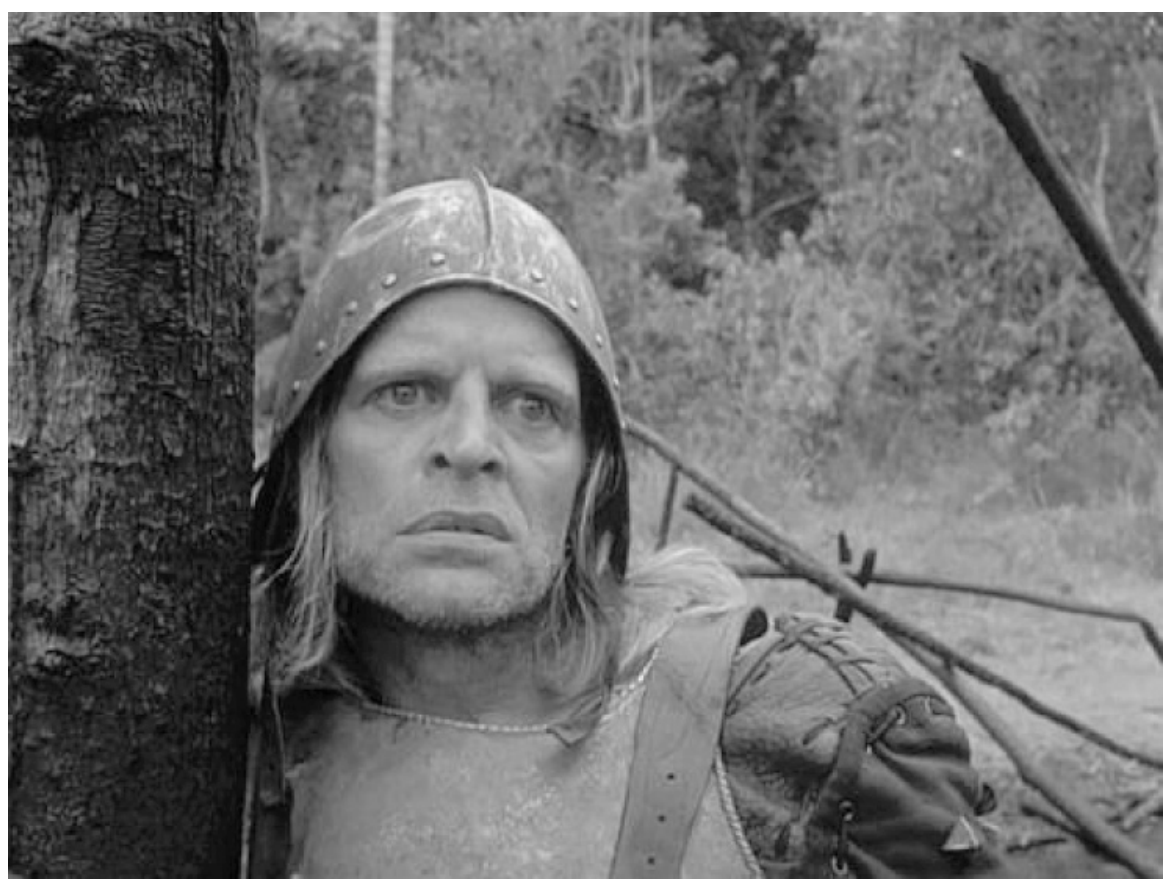

Fotograma del actor Klaus Kinski protagonizando a Lope de Aguirre. 
Aguirre, la cólera de Dios es el film que en 1972 dio a conocer internacionalmente a Werner Herzog 3 , uno de los padres del denominado nuevo cine alemán, y es la primera de sus cuatro épicas colaboraciones con el actor Klaus Kinski. La aventura equinoccial de Lope de Aguirre -como tituló Ramón J. Sénder a su novela sobre el personaje- fue un consistente cimiento sobre el cual Herzog erigió su discurso acerca de la desesperada búsqueda de una utopía que, al desafiar a las propias fuerzas humanas y a las de la naturaleza, finaliza en fracaso. Su Lope de Aguirre es un megalómano que parte en busca del mítico El Dorado, un supuesto país forjado en oro, Se cree que los propios indígenas inventaron dicho lugar de El Dorado para liberarse de la opresión de los españoles.

La obra de Herzog es única en cuanto a sus personajes, fuera de los cánones sociales y del todo antihéroes, como Klaus Kinski interpretando a Lope de Aguirre. También la obra del alemán es única por las imágenes, plenamente inéditas, que hacen del espectador un explorador de mundos desconocidos. En definitiva, ésta es una película de las denominadas "cine de autor", es una obra de arte, única e irrepetible, que fue muy bien acogida entre el público, sobre todo, un público intelectual y de cinéfilos.

La historia, contada por Werner Herzog, nos muestra la vorágine de la selva unida a la desmedida ambición que, cual agujero negro, va tragándose a los hombres. Aguirre pretende superar a Dios, y para ello, en su locura equinoccial, planea casarse con su propia hija para asegurar la pureza de una nueva raza y dominar al Nuevo Mundo.

En cuanto a los aspectos técnicos, hay que subrayar las numerosas afinidades que la película tiene en relación al género cinematográfico del documental, pues se recrea ampliamente en determinados planos sobre todo en los de la naturaleza, lo que da cierta lentitud a la narrativa fílmica. Es muy recurrente la utilización de la "cámara al hombro", y de los planos subjetivos que hacen más partícipe al espectador. Esa inclinación del director del film por el género documental es corroborada en el tratamiento que reciben los colores, predominando los tonos apagados, y la ausencia de diálogos y de la música incidental en determinadas secuencias.

Acerca de la inspiración y la realización del guión del film Aguirre, la cólera de Dios, su director, Werner Herzog, nos comenta ${ }^{4}$ al respecto:

\begin{abstract}
"Prácticamente no hay documentos históricos sobre Lope de Aguirre, apenas quince páginas, mucho sobre Aguirre es invención, pero es un personaje fantástico, posiblemente uno de los primeros que tenía una visión de la independencia de Latinoamérica, muy personal por supuesto. La historia no lo ha descrito como un buen hombre, porque no es vencedor, es un perdedor. El origen de la película es bien extraño, un día en la casa de un amigo estaba mirando unos libros y de repente en un libro para jóvenes sobre descubrimientos y aventuras,
\end{abstract}

\footnotetext{
3 La ficha Técnica y Artística de la película responde a lo siguiente: Género: Aventuras / Drama País: Alemania. Año: 1972 Duración: 118 min. Klaus Kinski - Don Lope de Aguirre/Cecilia Rivera - Elvira /Ruy Guerra - Don Pedro de Ursúa/Helena Rojo - Inés de Atienza/Del Negro - Hermano Gaspar de Carvajal/Peter Berling - Don Fernando de Guzmán/Daniel Ades - Perucho/Armando Polanah - Armando/Edward Roland Okello/Alejandro Chávez, Antonio Márquez, Daniel Farfán, Julio Martínez, Alejandro Repullés y los indios de la Cooperativa Lauramarca. http://www.tumbaabierta.com/ cripta/aguirre2.htm. 4 http://www.temakel.com/cineeherzog.htm.
} 
era un libro pésimo, pero de repente vi parte de una página, no más de veinte líneas sobre Lope de Aguirre y era tan fascinante que esa misma noche empecé a escribir un guión, que terminé en dos días y medio. Gran parte lo escribí en un viaje en autobús con mi equipo de fútbol y como encargamos bastante cerveza todos se emborracharon durante las primeras dos horas y yo defendiendo mi máquina de escribir sobre mis rodillas, tenía que empujar a cada uno de ellos que últimamente vomitaba, por eso algunas de las páginas no se pudieron salvar, echadas fuera de la ventana por el olor insoportable, algunas escenas que he olvidado. Después en una librería he encontrado algunos documentos sobre Aguirre, como la famosa carta al rey Felipe II, la carta del rebelde, que se llama La ira de Dios y el gran traidor”.

Las secuencias que comentamos en el presente artículo tienen como principal criterio de selección una finalidad crítica y, sobre todo de aplicación docente, siempre contrastando la diferencia entre el lenguaje cinematográfico, plagado de elipsis, y el rigor histórico. No olvidemos que el cine es el arte de la elipsis por ello jamás podemos comparar un texto literario con uno cinematográfico.

\section{Primeras Secuencias Seleccionadas (5 primeros minutos)}

El largometraje comienza con una breve descripción del contexto espacio-temporal que nos anticipa a las coordenadas en las que va a desarrollarse la acción, según la Crónica del dominico Gaspar de Carvajal $^{5}$ y aunque no es del todo correcta la fuente histórica, Werner Herzog recurre a la misma para mostrar las características de toda expedición que, partiendo de los Andes, tuviera como objetivo llegar a la selva amazónica en pos de El Dorado.

Bajo una densa niebla y los coros de la banda sonora del grupo germano Popol Vugh nos vamos introduciendo a través de la música incidental en un una ambientación, casi mística y onírica, que poco a poco nos irá desvelando la imponente cordillera andina en su vertiente oriental, valga la redundancia, orientada a la selva amazónica. Llega ante el espectador la imagen celeste e impactante de los Andes; el director usa aquí uno de sus grandes recursos: la naturaleza como protagonista, con peso inconfundible y taxativo, algo que es muy propio del cine teutón. Con impresionantes picados, contrapicados y movimientos de cámara se enfatiza la sensación de grandeza de la propia naturaleza, que siempre está muy por encima de los hombres, haciéndonos sentir como hormigas, como procesionarias invasoras de mundos inexplorados. El ser humano es nimio frente al medio natural, frente al paredón de los Andes Orientales que conducen a la Selva Amazónica.

La cámara elige la ladera de la montaña para presentarnos a la hueste, compuesta por el grueso humano y los avituallamientos que llevan consigo, resaltando la imagen

\footnotetext{
5 La crónica del padre dominico, Gaspar de Carvajal, se refiere la expedición de Gonzalo Pizarro, en la que Francisco de Orellana por el río Napo fue a la deriva hasta desembocar en el Amazonas y salir al mar; pero Werner Herzog tergiversa la Historia para hacernos creer que Gaspar de Carvajal fue el cronista de la expedición de Lope de Aguirre. La expedición de Orellana se produjo en la década de los cuarenta del siglo XVI, o sea, 20 años antes que la de Aguirre. (Nota de la Autora).
} 
de la rueda ${ }^{6}$ del cañón, invitándonos a reflexionar en torno a la inutilidad de la misma en semejantes parajes, tanto es así que civilizaciones como la Inca y sus antecesoras pudieron llegar a una alta complejidad cultural sin su utilización, a pesar de conocerla.

Observamos con detalle, casi de documental, la composición humana y material de la expedición, constituida por una inmensa mayoría de indígenas andinos, muchos de ellos encadenados y esclavizado, utilizados como bestias de carga y criados de los españoles; también acompañan las llamas (el camélido andino, animal de carga y tiro); los castellanos con pesadas armaduras, más propias de las guerras de Europa, totalmente inadecuadas a este medio natural; la litera de la hija de Lope de Aguirre; los animales de corral, los cerdos; la imagen religiosa de una Dolorosa; y al final un contrapicado de Lope de Aguirre y de su hija, bajando con dificultad la cordillera andina; y, sobre todo, se nos muestran las armas de fuego. Todo es una solemne procesión sin retorno hasta que un arma de fuego, un cañón, símbolo de la superioridad bélica que no cultural de Europa, cae estrepitosamente, rompiendo de forma violenta el clímax musical en el que estábamos inmersos tanto los actores como los espectadores. El cañón y su estruendo simbolizan la agresión de la conquista de América, el contraste entre lo salvaje y lo civilizado, el binomio barbarie-civilización: ¿cómo irrumpe el hombre civilizado europeo en la selva?, irrumpe como un accidente, como un estruendo maligno que rompe el silencio y el equilibrio milenarios? ¿Son acaso éstos los dioses que esperaban los nativos?

Resumiendo, estas primeras secuencias de la obra de Herzog pueden definirse por su carácter casi de cine documental y por el papel del medio natural como principal protagonista, ya que por encima de todo ser viviente y de su coyuntural devenir, se encuentran los callados Andes y su niebla envolvente.

\section{Segundas Secuencias Seleccionadas (9 minutos del final)}

Un primer plano del río Amazonas como espejo de la selva nos introduce en los espejismos de una expedición compuesta por náufragos supervivientes, alucinados sin ilusión, que marchan a la deriva por el gran Amazonas. Esa sensación está magníficamente conseguida a través de movimientos de cámara (traveling) circulares, realizados con la cámara al hombro, que provocan en el espectador una sensación de angustia, de mareo y, por tanto, de mayor realismo. Igualmente aparecen magníficos contrapicados de un Lope de Aguirre (Klaus Kinski) tullido, un "contra-conquistador", que apenas habla, sólo su rostro delata su locura equinoccial. En estas secuencias observamos también como Werner Herzog nos revela que la tecnología bélica superior de los europeos, materializada en las armas de fuego, poca utilidad tiene en un medio natural, hostil y sobrecogedor, en el que el silencio de la barbarie se impone a través de sutiles flechas envenenadas. Todos van cayendo poco a poco, víctimas de las fiebres y de las flechas, imponiéndose la naturaleza y la barbarie natural al etnocentrismo y antropocentrismo europeos.

En las últimas escenas el director se recrea en el rostro de Lope de Aguirre, solo, como se ve todo aquel que ambiciona el poder, solo en una rudimentaria embarcación,

6 En varios yacimientos de época prehispánica se han hallado juguetes de figuras con ruedas en determinados ajuares de clases sociales más altas, lo que denota el conocimiento de la existencia de la rueda en las culturas andinas prehispánicas; pero su innecesaria aplicación en un medio natural como los Andes. (Nota de la Autora). 
pero acompañado de una gran manada de monos carroñeros. Lope sueña en casarse con su hija para crear la dinastía más pura que haya existido sobre la faz de la tierra, e independizar a América de España. Quizás en este punto, Herzog se mofa de la máxima nazi de la raza aria. La cámara enfoca al sol ardiente y en su plenitud, símbolo del poder en todas las culturas, en contraste con el ocaso de Lope de Aguirre, su final y total deterioro causado por la soledad que acompaña a toda forma de poder. Los movimientos de cámara (travelling) circulares de estas escenas tienen como finalidad mostrarnos la marcha a la deriva, el sin sentido y la locura de la orgía del poder.

\section{El Aguirre (Klaus Kinski) de Werner Herzog}

En un principio observamos que el personaje no destaca por encima del grueso expedicionario. Este vasco hidalgo, venido a menos, físicamente se asemeja a un cuervo tullido, sin una complexión agraciada para lo que el oficio de conquistador pudiera demandar. Paulatinamente, se van revelando pinceladas discretas de su peculiar manera de concebir el proyecto conquistador: probablemente, cegado por su ambición delirante, él tiene un plan ya trazado desde mucho tiempo antes.

A partir de entonces, Aguirre comenzará a acechar en un segundo plano, siempre entre bastidores, tramando, tergiversando, maquinando, enfrascado en sus pensamientos y en un silencio que semeja un muro y que impide al espectador participar o prevenirse. Aguirre no habla directamente con sus incondicionales, quienes utilizan con él un doble lenguaje, que tanto al resto de protagonistas como al espectador nos está vedado, y de ahí lo oscuro del personaje, su ambigüedad. No se mancha las manos de sangre por su condición de noble y por ello delega el "trabajo sucio" en otros de clase inferior.

Para que toda esta tela de araña tejida tenga un sentido, el vasco utilizará las debilidades de los soldados, de los hombres, alentando su codicia y los deseos de oro y riquezas; y comparando la búsqueda de Eldorado a la historia de Hernán Cortés en su lucha y victoria sobre los aztecas en México.

Así llegamos a la carta escrita a Felipe II -retocada para que encaje en la versión que la película muestra-. Dicha carta refleja las verdaderas intenciones de Aguirre de cara a la Historia, dando un paso más del que dieran Cortés o Pizarro. Nuestro personaje está consumido por la prepotencia violenta y las ansias de poder hasta llegar al delirio como lo corrobora su propio testimonio o carta que, el director Werner Herzog, adapta al guión cinematográfico:

"Yo soy el mayor traidor. No debe haber ninguno más que yo. El que albergue siquiera el pensamiento de huir, será convertido en ciento noventa pedazos. Y sus pedazos serán después pisoteados hasta que se pueda untar con él una pared. El que coma un grano más de maíz o beba una gota más de agua será encerrado en prisión durante ciento cincuenta años. Cuando, yo, Aguirre, quiero que los pájaros caigan muertos de los árboles, los pájaros caen muertos de los árboles. Yo soy la cólera de Dios. La tierra sobre la que camino me ve y tiembla. Aquél que nos siga a mí y al río obtendrá una riqueza sin igual; pero aquél que deserte...". 


\section{3.- LOPE DE AGUIRRE, SEGÚN EL DORADO DE CARLOS SAURA7}

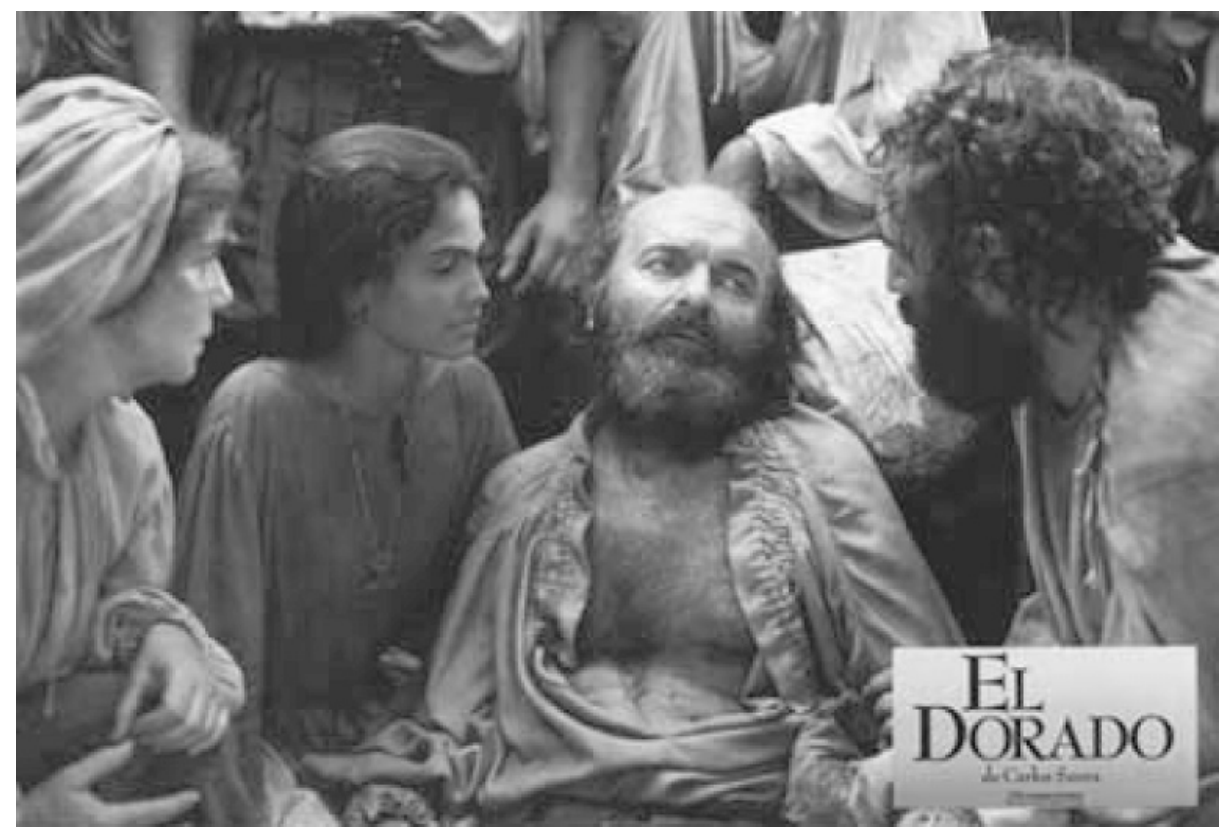

Fotograma de la Película "El Dorado" de Carlos Saura. Omero Antoniotti protagonizando a Lope de Aguirre.

El espectador es testigo de los acontecimientos que se desarrollan desde el campamento base de la salida de la expedición hasta poco antes de llegar al mar, conociendo el fin de la historia por una voz en off. La película, que destaca por su espectacular puesta en escena, es muy valiosa desde el punto de vista de la recreación histórica puesto que narra los principales avatares de la expedición tal y como fueron recogidos en las crónicas de Pedrarias de Almesto y Francisco Vázquez. Es, por tanto, la obra de Saura más fiel a la Historia que la de Werner Herzog y, al mismo tiempo, extremadamente descriptiva de la realidad.

Recordemos, además, que "El Dorado" fue en su día la película más cara de toda la historia del cine español (1000 millones de las antiguas pesetas), inversión que tuvo su mejor fruto en la plasmación visual del mundo de la hueste indiana, tema para el cual es una película esencial, aunque peca de una excesiva duración y de un ritmo demasiado lento que le restan frescura y atractivo de cara a públicos mayoritarios. De hecho, la

\footnotetext{
7 Año 1988. /Países: España, Francia e Italia /Género: Drama-Aventura. /Dirección Guión: Carlos Saura. /Música: Alejandro Massó/ Fotografía: Teo Escamilla/Producción: Andrés Vicente Gómez./ Dirección Artística: Peta Button./ Diseño de Producción: Terry Pritchard/Montaje Pedro del Rey/Vestuario Gerardo Vega. Duración 123 minutos. Presupuesto: 1000 millones de pesetas (6 millones de euros). Lugar de rodaje: Costa Rica Diseño de Producción: Terry Pritchard. Montaje: Pedro del Rey. REPARTO: Omero Antoniotti (Lope de Aguirre), Inés Sastre (Elvira), Lambert Wilson (Ursúa), José Sancho (La Bandera), Francisco Algora (Llamoso). Eusebio Poncela (Guzmán), Gabriela Roel (Inés), Feodor Atkine (Montoya), Patxi Bisquert (Pedrarias de Almesto), Francisco Merino (Alonso Esteban), Gladys Catania (Juana), Alfredo Catania (Vargas), Mariano González (Zalduendo), Gustavo Rojas (Carrión).
} 
película original de Saura es bastante más larga que la versión "cortada" que se puede encontrar en vídeo (en su día y tras el estreno cinematográfico se exhibió la versión completa en televisión a modo de capítulos)

Siguiendo una finalidad crítica y docente acerca del valor de las fuentes cinematográficas, hemos seleccionado varias secuencias del principio y del final de la película de las que ofrecemos una versión desde un doble lenguaje, a saber, el fílmico y el histórico.

\section{Primeras Secuencias Seleccionadas (8 minutos del inicio de la película)}

Estos 8 minutos constan de 3 secuencias perfectamente definidas:

La primera nos revela a través de unas bellísimas imágenes acompañadas de una música incidental de flauta el mito de El Dorado en la laguna Guatavita. Mito y ritual de los indígenas chibchas, que influyó como ningún otro a las expediciones españolas en busca de El Dorado que se albergaba en el fondo de la referida laguna. Así pues, la ceremonia del Dorado tenía lugar en la laguna de Guatavita (cerca de la actual Bogotá) y consistía en una ablución ritual al amanecer. El cacique de Guatavita se espolvoreaba con oro todo el cuerpo, una vez preparado con cierta goma, para darle adherencia. Acompañado de los principales hombres de la tribu, muy bien ataviados, iban a la laguna y en una balsa de junco arribaban hasta la mitad del lago. Allí, al surgir el sol sobre el horizonte, ocurría la ablución ritual; el jefe se sumergía totalmente en el agua, mientras los sacerdotes arrojaban las ofrendas, consistentes en objetos de oro, cerámica, cuentas, y joyas. Todo esto ocurría en un momento de extraordinario silencio. De las orillas salían grandes humaredas que, a modo incienso, solemnizaban el acto.

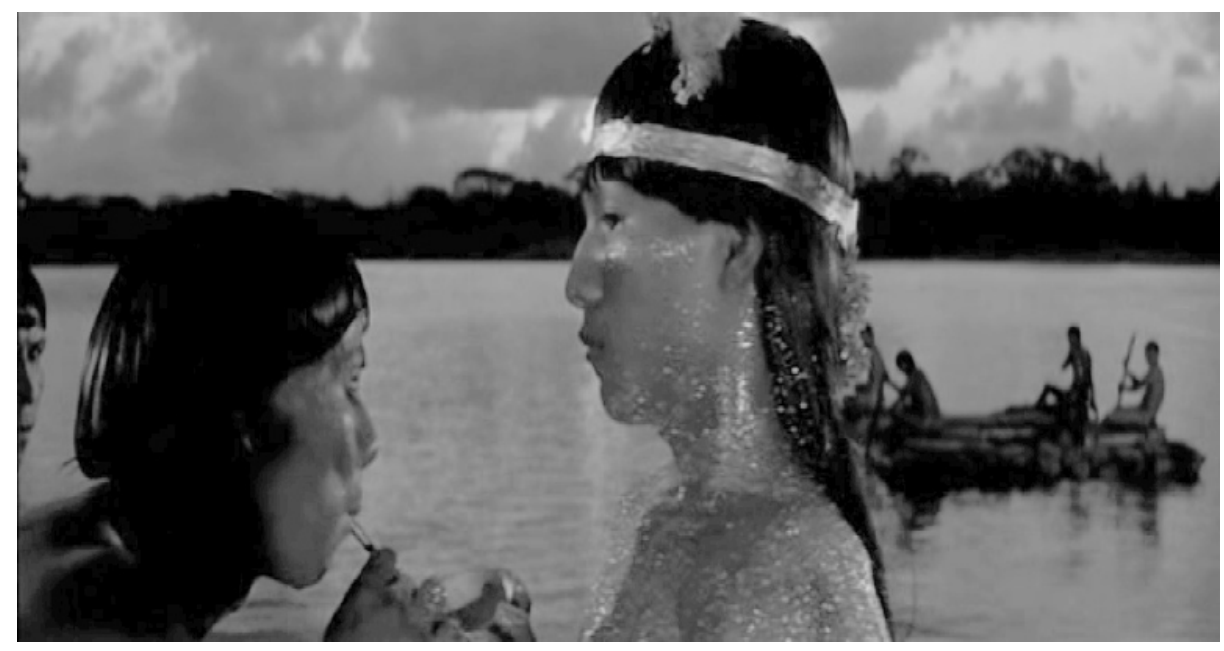

Fotograma de escenas del inicio de la película que aluden al baño ritual del cacique indígena que, espolvoreado de oro se sumerge en la laguna Guatavita.

La segunda secuencia nos sitúa en la vida cotidiana en el campamento de la selva antes de partir a la conquista de El Dorado; a diferencia de la película de Herzog nos 
encontramos con una hueste, ya instalada en la selva, nada se nos dice de cómo han llegado hasta allí desde el altiplano peruano, cosa que recrea de forma espectacular y a modo de documental la obra del director alemán. Saura se centra más en los detalles de la vida cotidiana y en los diálogos entre dos de los tres personajes femeninos que hay en la expedición: la hija de Lope de Aguirre (Elvira) y su dama de compañía, ambas hablan de doña Inés, la amante de Ursúa, el jefe de la expedición. En la conversación entre las mujeres (la hija de Lope de Aguirre y su cuidadora o dama de compañía) está muy presente el tema racial, el fenómeno del mestizaje, y la difícil aceptación del mismo en una sociedad colonial de castas en la que los prejuicios raciales serían determinantes. En la obra de Saura la hija de Aguirre es mestiza, es una raza mezclada; y no aria (raza pura) como la del film de Herzog.

La tercera secuencia nos muestra la salida triunfal de la expedición tras la misa de acción de gracias, las campanas echan al vuelo, y todos salen del templo santificados para emprender la expedición a través de la selva en busca de El Dorado. Estas secuencias recuerdan el papel prioritario que tuvo la Iglesia en la conquista de América, la justificación teocrática de la misma, cosa que no refleja la obra de Herzog. La puesta en escena es espectacular, muy propia del cine comercial, con abundancia de extras, de soldados, todos de raza blanca, como si de los ejércitos de Flandes se tratara; lo cual no es real, ya que la hueste indiana no era monocolor: toda expedición estaba acaudillada por una minoría blanca y el resto la componían mestizos e indígenas, estos últimos en calidad de sirvientes y esclavos (como muy bien lo refleja la obra de Herzog). En esta secuencia se alude a la expedición de Francisco de Orellana que, unos 18 años antes, había surcado el Amazonas hasta su desembocadura; y Alonso de Esteban, capitán de la de Orellana, acompaña a Ursúa en esta nueva aventura hacia El Dorado; aunque Alonso de Esteban fuese hombre experimentado, sin embargo su voz es la de la ilusión y la del mito más que la de la experiencia, Alonso de Esteban, casi siempre embriagado, jura haber visto a las amazonas. Igualmente en esta secuencia hay un despliegue espectacular en torno al personaje de doña Inés, mestiza adornada con joyas de oro de diseño indígena (probablemente expoliadas), amante de Pedro de Ursúa, mujer objeto de admiración para unos y de envidia para otros.

\section{Segundas Secuencias seleccionadas (8 Minutos)}

La primera secuencia nos muestra a un Lope de Aguirre paternal, cuidador, desvelado, y velando el sueño de su hija, que es su futuro, su proyecto, que es la razón de su vida y, quizá, de su locura equinoccial. Ésta es una escena íntima y, a mi modo de ver, entrañable.

La segunda secuencia nos muestra al Lope de Aguirre público, al que se hace con la jefatura de la expedición después de haber liquidado a Alonso de Guzmán, al que puso en el poder tras haber eliminado a Pedro de Ursúa. En esta secuencia nos hallamos ante un predominio de planos medios, movimientos de cámara avant junto con un continuado diálogo de cámara subjetiva, a lo que se le une una magnífica ambientación histórica. Todo ello introduce al espectador en la historia desde el análisis del discurso no sólo verbal sino extra-verbal: los gestos, los rostros son como si contemplásemos el más puro arte del retrato barroco, y es ese arte del retrato lo que humaniza a Lope de Aguirre y a su, casi rendida, expedición. Todos lo veneran y su hija no le quita ojo de 
encima. El Lope de Aguirre que nos muestra Saura es el precursor de la independencia americana, es el príncipe de la libertad que inaugura para América un nuevo orden social y racial igualando a negros, indios, mestizos y españoles. Y en esta situación declara su independencia de España con la carta, que presentamos al final en calidad de Apéndice Documental; aunque el texto del film está retocado para adaptarse al mismo. A través de las palabras de Lope de Aguirre conocemos como toda empresa de descubrimiento y conquista siempre tuvo un carácter privado, eran los particulares los que ponían el riesgo, el dinero, los medios de producción y los hombres; mientras que el rey de España estaba exento de contribuir , sólo daba su autorización y a cambio de la misma recibía el quinto real; es decir la quinta parte de la riqueza que se obtuviera de la empresa particular; pero si la empresa era un fracaso, la Corona jamás perdía, nunca arriesgaba. Por ello Lope de Aguirre en su carta pretende mostrar la injusticia de la Corona que siempre gana y nada arriesga; mientras los particulares pierden vida y haciendas. La secuencia termina con imágenes del río, de la selva y de una expedición estancada (no a la deriva como en la obra de Werner Herzog), estancada en la selva, desamparada, cobrando importancia un paisaje natural junto con los ruidos de la selva como banda sonora, cantos de pájaros con un carácter musical diegético. Saura, a diferencia de Herzog, da más importancia a los diálogos de los actores o del actor principal, Lope de Aguirre, que al paisaje; éste es sólo telón de fondo pero no tiene el protagonismo que adquiere en el Aguirre del director teutón. La naturaleza en la obra de Saura es telón de fondo y no protagonista. Sin embargo los personajes adquieren una singular protagonismo, casi podríamos hablar de una visualización teatral y antropocéntrica, tan magistralmente ambientada que cualquier fotograma podría asimilarse a la pintura barroca, a veces, tenebrista de la época.

\section{4.- APÉNDICE DOCUMENTAL: LA CARTA DE LOPE DE AGUIRRE}

La carta. La famosa carta ${ }^{8}$ de Lope de Aguirre dirigida a Felipe II es hoy todo lo que queda de aquella trágica expedición del Dorado. En sendas obras cinematográficas sólo escuchamos extractos de la misma. Con ácida ironía, Aguirre denuncia a aquellos que en nombre del rey se rebelan contra él de manera hipócrita. En ella hay también una fuerte crítica al papel jugado por la Iglesia durante la conquista, denunciando las actitudes nada cristianas de muchos sacerdotes, más ocupados en las riquezas y títulos que en la fe de indios y españoles. No es un grito libertario, pues aunque se enfrenta a la autoridad real, no reivindica más que el derecho del conquistador a disfrutar de lo conquistado, porque, en la realidad, eran los emisarios reales y otros cargos, no implicados en guerras, los que acababan siendo dueños del "trabajo" de otros, y el mismo monarca se beneficiaba sin implicarse lo más mínimo en los asuntos de Indias, ya que de todos los beneficios hallados (minas de oro y/o plata, pesquerías de perlas, etc) la Corona, sin esfuerzo alguno y sólo por autorizar la expedición o las explotaciones, recibía la quinta parte de lo hallado. La carta no es otra cosa que la queja del conquistador, del artífice material e ideal de la conquista, de ese hombre empujado, muchas veces por el hambre en España, a unas guerras y aventuras de las que es protagonista pero de las que

8 MAMPEL GONZÁLEZ, Elena y ESCANDELL TUR, Neus: Lope de Aguirre: Crónicas, 1559-156. Barcelona, Universidad de Barcelona, 1981. pp. 255- 259. 
se benefician otros, como la Corona y los burócratas apegados al poder político. Esta carta nos debe hacer reflexionar acerca de quiénes son los verdaderos protagonistas de la historia oficial, muchas veces oscuros y serviles burócratas que manipulan y mueven los hilos de la Historia en la sombra.

Rey Felipe, natural español, hijo de Carlos, invencible:

Lope de Aguirre, tu mínimo vasallo, cristiano viejo, de medianos padres hijosdalgo natural vascongado, en el reino de España, en la villa de Oñate vecino, en mi mocedad pasé el mar Océano a las partes del Pirú, por valer más con la lanza en la mano, y por cumplir con la deuda que debe todo hombre de bien; y así, en veinte y cuatro años, te he hecho muchos servicios en el Pirú, en conquistas de indios, y en poblar pueblos en tu servicio, especialmente en batallas y reencuentros que ha habido en tu nombre, siempre conforme a mis fuerzas y posibilidad, sin importunar a tus oficiales por paga, como parescerá por tus reales libros.

[...]Mira, mira, Rey español, que no seas cruel a tus vasallos, ni ingrato, pues estando tu padre y tú en los reinos de Castilla, sin ninguna zozobra, te han dado tus vasallos, a costa de su sangre y hacienda, tantos reinos y señoríos como en estas partes del mundo tienes. Y mira, Rey y señor, que no puedes llevar con título de Rey justo ningún interés destas partes donde no aventuraste nada, sin que primero los que en ello han trabajado sean gratificados

Por cierto lo tengo que van pocos reyes al infierno, porque sois pocos; que si muchos fuéredes, ninguno podría ir al cielo, porque creo allá seríades peores que Lucifer, según tenéis sed y hambre y ambición de hartaros de sangre humana; mas no me maravillo ni hago caso de vosotros, pues os llamáis siempre menores de edad, y todo hombre inocente es loco; y vuestro gobierno es aire. $Y$, cierto, a Dios hago solemnemente voto, yo y mis doscientos arcabuceros marañones, conquistadores, hijosdalgo, de no te dejar ministro tuyo a vida, porque yo sé hasta dónde alcanza tu clemencia; el día de hoy nos hallamos los más bien aventurados de los nascidos, por estar como estamos en estas partes de Indias, teniendo la fe y mandamientos de Dios enteros, y sin corrupción, como cristianos; manteniendo todo lo que manda la Santa Madre Iglesia de Roma; y pretendemos, aunque pecadores en la vida, recibir martirio por los mandamientos de Dios. [...] Especialmente es tan grande la disolución de los frailes en estas partes, que, cierto, conviene que venga sobre ellos tu ira y castigo, porque ya no hay ninguno que presuma de menos que de Gobernador. Mira, mira, Rey, no les creas lo que te dijeren, pues las lágrimas que allá echan delante de tu Real persona, es para venir acá a mandar. Si quieres saber la vida que por acá tienen es entender en mercaderías, procurar y adquirir bienes temporales, vender los Sacramentos de la Iglesia por prescio; enemigos de pobres, incaritativos, ambiciosos, glotones y soberbios; de manera 
que, por mínimo que sea un fraile pretende mandar y gobernar todas estas tierras. Pon remedio, Rey y Señor, porque destas cosas y malos exemplos, no está imprimida ni fijada la fe en los naturales; $y$, más te digo, que si esta disolución destos frailes no se quita de aquí no faltarán escándalos. [...] Pues los frailes, a ningún indio pobre quieren absolver ni predicar; y están aposentados en los mejores repartimientos del Pirú, y la vida que tienen es áspera y peligrosa, porque cada uno dellos tiene por penitencia en sus cocinas una docena de mozas, y no muy viejas, y otros tantos muchachos que les vayan a pescar: pues a matar perdices y a traer fruta, todo el repartimiento tiene que hacer con ellos; que, en fe de cristianos, te juro, Rey y Señor, que si no pones remedio en las maldades desta tierra que te ha de venir azote del cielo; y esto dígolo por avisarte de la verdad, aunque yo y mis compañeros no queremos ni esperamos de ti misericordia. ¡Ay, ay!, qué lástima tan grande que, César y Emperador, tu padre conquistase con la fuerza de España la superbia Germania, que no te duelas de nuestra vejez y cansancio, siquiera para matarnos la hambre un día! Sabes que vemos en estas partes, excelente Rey y Señor, que conquistaste a Alemania con armas, y Alemania ha conquistado a España con vicios, de que, cierto, nos hallamos acá más contentos con maíz y agua, sólo por estar apartados de tan mala ironía, que los que en ella han caído pueden estar con sus regalos. Anden las guerras por donde anduvieron, pues para los hombres se hicieron; mas en ningún tiempo, ni por adversidad que nos venga, no dejaremos de ser sujetos y obedientes a los preceptos de la Santa Madre Iglesia romana. [...] Y otros muchos hijosdalgo desta liga, ruegan a Dios, Nuestro Señor, te aumente siempre en bien y ensalce en prosperidad contra el turco y franceses, y todos los demás que en estas partes te quisieran hacer guerra; y en estas nos dé Dios gracia que podamos alcanzar con nuestras armas el precio que se nos debe, pues nos han negado lo que de derecho se nos debía. Hijo de fieles vasallos en tierra vascongada, y rebelde hasta la muerte por tu ingratitud.

Lope de Aguirre, el Peregrino. 